\title{
o Outro Lado da Moeda: Israelenses/Judeus Sans Sionismo
}

\section{Claudia Stephan 1}

\section{RESUMO}

O conflito entre israelenses e palestinos é um tema polêmico e recorrente na mídia contemporânea. Sua repercussão, frequentemente, mostra o dualismo da questão, seja o lado da resistência ou "terrorismo" palestino, seja o lado "democrático" ou sionista israelense/judeu. Entretanto, há outra faceta dos israelenses/judeus não muito conhecida ou mesma divulgada pela mídia: a dos israelenses/judeus não sionistas pró-palestinos. São movimentos e organizações da sociedade civil de Israel e de comunidades judaicas em diversos países que visam a divulgar o judaísmo sans sionismo, assim como as frequentes violações ao Direito Internacional e às resoluções da Organização das Nações Unidas (ONU) pelo Estado de Israel, e oferecer suporte à Causa Palestina.

Palavras-chave: Conflito Árabe-Israelense; Sionismo; Direito Internacional; Judeus próPalestina; Questão Palestina.

O conflito entre israelenses/judeus ${ }^{2}$ e palestinos não é exatamente uma novidade, especialmente no meio acadêmico de Relações Internacionais. Sem focar na questão histórica e seus pormenores, seu marco data da criação do Estado de Israel, em 1948. Desde então, a mídia internacional se encarrega de divulgar os acontecimentos da região, ora esperançosos, ora trágicos (em sua maioria). Porém, é possível observar que os relatos, e mesmo estudos acadêmicos, limitam-se a apresentar apenas duas faces mais generalizadas do conflito: uma palestina de resistência e uma israelense/judaica

\footnotetext{
1 Claudia Stephan é internacionalista, especialista em Sociologia Política, mestranda pelo Programa de Pós-Graduação Stricto Sensu em Ciência Política na Universidade Federal do Paraná (UFPR) e pesquisadora do Núcleo de Estudos e Pesquisas em Relações Internacionais (NEPRI/UFPR).

20 termo "israelenses/judeus" foi escolhido pela autora com a intenção de englobar cidadãos israelenses judeus e não judeus, bem como judeus cidadãos de outros países. 
sionista $^{3}$. Um dualismo que simplifica e, por vezes, distorce, uma realidade complexa e multifacetada.

De um lado estão os palestinos, vítimas das violações diárias dos Direitos Humanos e do Direito Internacional pelo exército israelense. Ora retratados como vítimas resilientes, ora como terroristas impetuosos. Do outro lado, estão os israelenses/judeus, cidadãos do único Estado "democrático" do Oriente Médio. Ora retratados como vítimas do terrorismo palestino, ora como sionistas impiedosos.

Seja como for, e independente de verdades ou mentiras absolutas, este retrato ignora uma boa parcela da população israelense/judaica que luta por uma verdadeira democracia, pelo fim da ocupação dos territórios palestinos, pela autodeterminação dos povos, pelo respeito aos direitos humanos de seus semelhantes palestinos, bem como pela separação entre judaísmo e sionismo. São movimentos e organizações da sociedade civil israelense e de comunidades judaicas em diversos países que se mobilizam pela causa e pressionam governos por uma paz duradoura em Israel/Palestina. É, enfim, uma faceta do conflito entre israelenses/judeus e palestinos que não pode (e não deve) ser desconsiderada.

Uma destas iniciativas é o Jewish Voice for Peace (JVP), organização judaica de cunho progressista com base em Oakland, Califórnia - Estados Unidos, que propaga informações acerca dos acontecimentos em Israel e nos territórios ocupados, mas, principalmente, alerta a opinião pública norte-americana sobre os perigos do financiamento militar e a necessidade de tomar decisões concretas a respeito da ocupação e das violações aos direitos humanos, uma vez que a organização acredita que as grandes decisões políticas para Israel partem dos Estados Unidos (1996, s/n).

Segundo a própria organização, sua missão é “trabalhar para alcançar uma paz duradoura que reconheça os direitos tanto de israelenses quanto de palestinos para a segurança e a autodeterminação" (JVP, 1996, s/n - tradução livre). A JVP organiza

\footnotetext{
${ }^{3}$ Conforme Lewis (citado por HOUAT, 2006), o sionismo é um movimento baseado, em parte nas tradições religiosas judaicas e até certo ponto em uma versão judaica de novas ideologias nacionalistas em curso na época, condicionados pela necessidade de encontrar solução para a rejeição e opressão que sofriam na Europa. [...] Partindo da idéia de que os judeus ao redor do mundo, através de ligações religiosas, étnicas, culturais e ancestrais formariam uma única nação, e como tal precisariam de um Estado para onde essa nação pudesse convergir para escapar do antissemitismo e preservar a cultura judaica, foi criado o movimento sionista. [...] Usarei o termo 'sionista' no sentido mais radical: expansionista, conivente com a ocupação dos territórios palestinos e de negação das violações aos direitos humanos dos palestinos cometidas pelo Estado de Israel.
} 
campanhas de conscientização acerca do conflito entre israelenses e palestinos, trabalha com outras organizações - judaicas, árabes e outras, bem como promove uma política externa norte-americana com base na paz, na democracia e nos direitos humanos (1996, $\mathrm{s} / \mathrm{n})$.

Outra destas iniciativas é o Peace Now, uma das mais antigas organizações em prol da paz entre israelenses e palestinos, bem como do estabelecimento de um Estado Palestino dentro das fronteiras de 1967. Seus membros estão localizados tanto no Oriente Médio quanto em outros países. A organização, baseada em Israel, trabalha na promoção entre israelenses e palestinos, da solução de dois Estados, como única saída viável para o conflito. Sua missão é

promover a paz e a democracia através da educação do público israelense e cidadãos interessados de todo o mundo. Nós também esperamos inspirar o público a desenvolver iniciativas que possam dar suporte à promoção duradoura da paz e à remoção dos obstáculos existentes para a negociação política da solução de dois Estados (PEACE NOW, 1978, s/n - tradução livre).

Essa organização ainda conta com afiliações em outros países, como Amigos Brasileiros do Paz Agora, o qual foi formado em 2001 e promove, além do engajamento na causa, a manutenção das relações amigáveis entre judeus, árabes e outros povos no Brasil (2001, s/n).

A organização Rabbis for Human Rights (RHR) é outro exemplo de iniciativa própalestinos, porém de cunho religioso-social. Fundada em 1988, a organização é formada por judeus ortodoxos, reformistas, conservadores e de outras vertentes que promovem os direitos humanos de israelenses e palestinos de acordo com a tradição judaica, trabalhando com entidades de Israel e de outros países, pois acreditam, como seguidores da fé judaica, na igualdade dos homens perante Deus e na denúncia das injustiças $(1988, \mathrm{~s} / \mathrm{n})$.

Segundo a própria organização, sua missão é

advogar pelos direitos dos membros marginalizados da sociedade, defender os direitos das minorias em Israel e dos palestinos nos territórios ocupados, e na prevenção de violações flagrantes de direitos humanos básicos de trabalhadores estrangeiros (RHR, 1988, s/n - tradução livre).

Outra organização a citar é a Jews for Justice for Palestinians (JfffP), a qual é formada por judeus britânicos ou que vivem no Reino Unido, de diferentes vertentes, e que compartilham da "oposição às políticas israelenses que debilitam os meios de subsistência e os direitos humanos, civis e políticos do povo palestino" (2012, s/n - 
tradução livre). A JfJfP acredita que críticas à política destrutiva do Estado de Israel não devem ser consideradas como antissemitismo, defendem a volta às fronteiras de $1967 \mathrm{e}$ apoiam, inclusive financeiramente, outras entidades que se opõem à ocupação, sendo também responsáveis pela fundação de uma federação europeia de grupos judaicos European Jews for a Just Peace (2012, s/n).

Além das organizações acima citadas, diversas outras atuam na promoção dos direitos e da paz entre israelenses e palestinos, assim como na divulgação da realidade nos territórios ocupados. Algumas de cunho militar, como o movimento dos Refusenicks (desertores do exército israelense) e o Breaking the Silence (combatentes veteranos do exército israelense); outras de cunho religioso, como Jews not Zionists e True Torah Jews, que priorizam a separação entre judaísmo e sionismo; organizações de cunho político, como Gush Shalom, One Voice e Zochrot, dentre outras que priorizam aspectos econômicos, ambientais e afins.

É possível observar, então, que há uma faceta do conflito representada pelo ativismo político e humanitário, não somente de árabes e palestinos, mas também de israelenses e judeus de várias partes do mundo. E que, mesmo com uma grande parte da população israelense alheia aos trágicos fatos, a importância dessa faceta é inegável. Onde há movimentos de denúncia e mobilização, há possibilidade de mudanças.

Portanto, se faz necessária a exposição das diversas faces de um conflito e seu devido esclarecimento para o mundo - seja pela via acadêmica ou pela via societal pois, somente conhecendo todos os lados de uma dada situação, será possível formular uma solução que atenda a todas as partes.

\section{Referências Bibliográficas}

ABOUT. Jewish for Justice for Palestinians, Reino Unido, 2012. Disponível em: < http://jfjfp.com/?page_id=2>. Acesso em: 05/08/2012.

ABOUT EJJP. European Jews for a Just Peace, Holanda, 2002. Disponível em: < http://www.ejjp.org/>. Acesso em: 05/08/2012. 
ABOUT Jewish Voice for Peace. Jewish Voice for Peace, Estados Unidos, 1996. Disponível em: < http://jewishvoiceforpeace.org/about>. Acesso em: 05/08/2012.

ABOUT One Voice. One Voice, Israel/Territórios Ocupados, 2004. Disponível em: < http://onevoicemovement.org/about-onevoice/>. Acesso em: 05/08/2012.

ABOUT us. Breaking the Silence, Israel, 2004. Disponível em: < http://www.breakingthesilence.org.il/about/organization>. Acesso em: $05 / 08 / 2012$.

ABOUT us. Rabbis for Human Rights, Israel, 1988. Disponível em: < http://rhr.org.il/eng/index.php/about/>. Acesso em: 05/08/2012.

AIMS of Gush Shalom. Gush Shalom, Israel, 2012. Disponível em: < http://zope.gushshalom.org/home/en/about/aims/>. Acesso em: 05/08/2012.

HOUAT, Stephan Fernandes. A criação do Estado de Israel e um Estado único como solução dos conflitos. Trabalho de Graduação (Bacharelado em Direito) Centro Universitário do Pará. Belém, 2006.

MUSIH, N. Learning the Nakba as a Condition for Peace and Reconciliation - who we are. Zochrot, Israel, 2002. Disponível em: < http://www.nakbainhebrew.org/en/>. Acesso em: 05/08/2012.

OUR mission. True Torah Jews Against Zionism, Brooklyn-NY, 2012. Disponível em: < http://truetorahjews.info/>. Acesso em: 05/08/2012.

POWELL, B. A. Refusenicks: Three Israeli soldiers tell why they will not serve in the occupied territories. UC Berkeley News, Califórnia, 13 março 2003. Disponível em: < http://berkeley.edu/news/media/releases/2003/03/13_refuseniks.shtml>. Acesso em: 05/08/2012.

QUEM somos. Amigos Brasileiros do Paz Agora, Brasil, 2001. Disponível em: < http://www.pazagora.org/quem-somos/>. Acesso em: 05/08/2012.

WELCOME to jewsnotzionists.org. Jews not Zionists, Brooklyn-NY, 2012. Disponível em: < http://www.jewsnotzionists.org/>. Acesso em: 05/08/2012.

WHO we are. Peace Now, Israel, 1978. Disponível em: < http://peacenow.org.il/eng/content/who-we-are>. Acesso em: 05/08/2012. 